\title{
Synthesis and Thermal Behavior of Cordierite Ceramics from Algerian Kaolin and Magnesium Oxide
}

\author{
D. Redaoui ${ }^{a, b}$, F. SAhnoune ${ }^{b, c, *}$, A. Ounli ${ }^{a, b}$ And N. SAheB ${ }^{d}$ \\ ${ }^{a}$ Physics and Chemistry of Materials Lab, University Mohamed Boudiaf of M'sila, 28000 M'sila, Algeria \\ ${ }^{b}$ Physics Department, Faculty of Science, University Mohamed Boudiaf of M'sila, 28000 M'sila, Algeria \\ ${ }^{c}$ Research Unit on Emerging Materials (RUEM), Ferhat Abbas of Setif 01, 19000 Setif, Algeria \\ ${ }^{d}$ Department of Mechanical Engineering, King Fahd University of Petroleum and Minerals, \\ 31261 Dhahran, Saudi Arabia

\begin{abstract}
Kaolin DD1 (from Djebel Debbagh, Guelma, Algeria), kaolin Tamazarte KT (from Jijel, Algeria) and magnesium oxide $\mathrm{MgO}$ mixtures with relative weight ratios of $59 / 29 / 12$ have been studied in this work in order to obtain cordierite ceramics with the stoichiometric formula $\left(2 \mathrm{MgO} \cdot 2 \mathrm{Al}_{2} \mathrm{O}_{3} \cdot 5 \mathrm{SiO}_{2}\right)$, by mixing raw materials abundant in Algeria. Thermogravimetric analysis and differential thermal analysis were carried out on powder from room temperature to $1300^{\circ} \mathrm{C}$, at heating rates from 10 to $50{ }^{\circ} \mathrm{Cmin}^{-1}$. The phases and their transformations were determined by X-ray diffraction for the mixture of kaolin (59 wt.\% DD1 + 29 wt.\% KT) and 12 wt.\% of magnesium oxide powder treated at different temperatures between 900 and $1250{ }^{\circ} \mathrm{C}$ for $2 \mathrm{~h}$. The activation energies of $\alpha$-cordierite formation calculated from isothermal data were around $372 \mathrm{~kJ} \mathrm{~mol}^{-1}$. The average Avrami parameter is found to be around 1.95 for each heating rate.
\end{abstract}

DOI: 10.12693/APhysPolA.134.71

PACS/topics: ceramics, differential thermal analysis, powders

\section{Introduction}

Cordierite $\left(2 \mathrm{MgO} \cdot 2 \mathrm{Al}_{2} \mathrm{O}_{3} \cdot 5 \mathrm{SiO}_{2}\right)$ is a technically important class of advanced technological materials in different branches of industry, because of its excellent thermal shock resistance, low dielectric constant, low thermal expansion coefficient, high resistivity and chemical stability, high mechanical strength, good mechanical properties and ability to be co-fired with high conductivity electrodes [1-8].

Cordierite is one of the ceramic materials which has been utilized as a catalyst carrier in industry of automobile exhaust systems, microelectronics, refractory material, integrated circuit boards, filters for molten metals, thermal shock-resistant tableware, porous ceramics and holders for electrical heaters $[2,5]$.

In order to synthesize cordierite ceramics at lower temperatures, various methods were used, such as coprecipitation [9], the Pechini method, sol-gel processes or the re-crystallisation of the molten glasses with cordierite composition [10]. The most usually used method of processing the cordierite ceramics is solid-state reaction $[2-6,11]$. It is synthesized from pure oxides $\mathrm{Al}_{2} \mathrm{O}_{3}$, $\mathrm{MgO}$, and $\mathrm{SiO}_{2}$ or nitrates or synthesized from talc and clays, kaolinite and alumina as raw natural materials [10].

The main objective of this work is to investigate the possibility of preparing cordierite from Algerian raw natural materials: kaolin of DD1 and Tamazarte KT mixed

*corresponding author; e-mail: sahnounefoudil@yahoo.com with the synthetic magnesium oxide $\mathrm{MgO}$. The crystallization behavior was studied using thermogravimetric analysis (TG) and differential thermal analysis (DTA) techniques. The crystalline phases were identified using X-ray diffraction. The crystallization kinetics was examined in order to determine the activation energies of cordierite formation and the growth morphology parameters, such as the Avrami parameter $n$.

\section{Materials and methods}

Kaolin of DD1 (source of $\mathrm{SiO}_{2}$ and $\mathrm{Al}_{2} \mathrm{O}_{3}$ ), from Djebel Debbagh, Guelma region in Algeria, kaolin Tamazarte $\mathrm{KT}$ (from Jijel, Algeria), as source of $\mathrm{SiO}_{2}$, and the synthetic magnesium oxide $\mathrm{MgO}$ were mixed together in a stoichiometry corresponding to composition of cordierite $\left(2 \mathrm{MgO} \cdot 2 \mathrm{Al}_{2} \mathrm{O}_{3} \cdot 5 \mathrm{SiO}_{2}\right)$.

Sixteen grams of kaolin (DD1+KT) and magnesium oxide with $120 \mathrm{ml}$ of ethanol were milled in planetary ball mill using zirconia balls (15 $\mathrm{mm}$ in diameter) for $5 \mathrm{~h}$ at a speed of $250 \mathrm{revmin}^{-1}$. The slurry was dried in an oven at $150{ }^{\circ} \mathrm{C}$ for $24 \mathrm{~h}$. After that the material was crushed manually. DTM is the abbreviation of the starting materials.

Thermal behavior of DTM powder was determined using Setaram Labsys Evo TG-DTA $1600^{\circ} \mathrm{C}$ equipment in the temperature range between room temperature and $1400{ }^{\circ} \mathrm{C}$ under argon gas flow $\left(40 \mathrm{~cm}^{3} \mathrm{~min}^{-1}\right)$ at various heating rates. The crystalline phases of DTM powder formed during sintering were identified using Bruker D8 Advances diffractometer with $\mathrm{Cu} \mathrm{K}_{\alpha}$ radiation and a Ni filter, with a scan step of $0.0167^{\circ}$, operated at $40 \mathrm{kV}$ and $40 \mathrm{~mA}$. 


\section{Results and discussion}

Figure 1 presents the DTA/TG, DTG/T curves of DTM powder for the heating rate of $20^{\circ} \mathrm{Cmin}^{-1}$. The TG curve shows two mass losses. The first mass loss of around $1.5 \%$ is observed in the temperature range of 50 $230^{\circ} \mathrm{C}$. It corresponds to the evaporation of adsorbed water. This reaction correlates with the first endothermic peak at $120^{\circ} \mathrm{C}$ in DTA curve and first endothermic peaks at $113^{\circ} \mathrm{C}$ in the DTG curve.

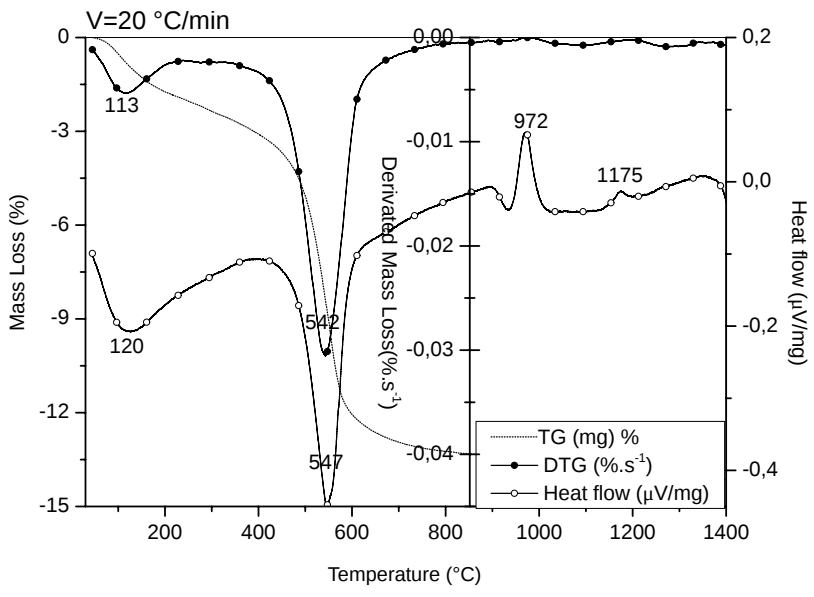

Fig. 1. DTA/TG, DTG/T curves of DTM powder heated at $20^{\circ} \mathrm{Cmin}^{-1}$.

The second mass loss equal to $12.5 \%$ can be attributed to the dehydroxylation of kaolinite and the formation of metakaolinite. This reaction corresponds to the second endothermic peak at $547^{\circ} \mathrm{C}$ in the DTA curve and at $542{ }^{\circ} \mathrm{C}$ in the DTG curve.

As can be seen from the DTA curve, there are two exothermic peaks exhibited at 972 and $1175^{\circ} \mathrm{C}$, respectively. The first peak at $972{ }^{\circ} \mathrm{C}$ refers to the formation of mullite phase. The last peak at $1175^{\circ} \mathrm{C}$ corresponds to the formation of $\alpha$-cordierite, as was proven later by the $\mathrm{XRD}$ analysis.

XRD analysis, as seen in Fig. 2, shows that the DTM powder which was heat treated at 950, 1050, 1150 and $1250^{\circ} \mathrm{C}$ for $2 \mathrm{~h}$, contains several crystalline phases, such as magnesium silicate $\mathrm{Mg}_{2} \mathrm{SiO}_{4}$, sapphirine $\mathrm{Mg}_{19.12} \mathrm{Al}_{45.24} \mathrm{Si}_{11.64} \mathrm{O}_{80}$, mullite $\mathrm{Al}_{4.5} \mathrm{Si}_{1.5} \mathrm{O}_{9.74}$, cristobalite $\mathrm{Si}_{4} \mathrm{O}_{8}$ and $\alpha$-cordiarite $\mathrm{Mg}_{4} \mathrm{Al}_{8} \mathrm{Si}_{10} \mathrm{O}_{36}$.

At $950{ }^{\circ} \mathrm{C}$ magnesium silicate and sapphirine were the only phases present. At temperature of $1050^{\circ} \mathrm{C}$, mullite phase began to appear and the sapphirine phase was observed too.

Figure 3 shows the DTA curves of DTM powder in the temperature range $1120-1260^{\circ} \mathrm{C}$ for various heating rates between $10-50^{\circ} \mathrm{Cmin}^{-1}$. The exothermic peak shifts to high temperature from 1155 to $1203^{\circ} \mathrm{C}$ and increases along with the increase of heating rate from 10 to $50^{\circ} \mathrm{Cmin}^{-1}$.

From the DTA results the crystallized fraction of DTM powder can be calculated using equation $x=A_{T} / A_{0}$ ver-

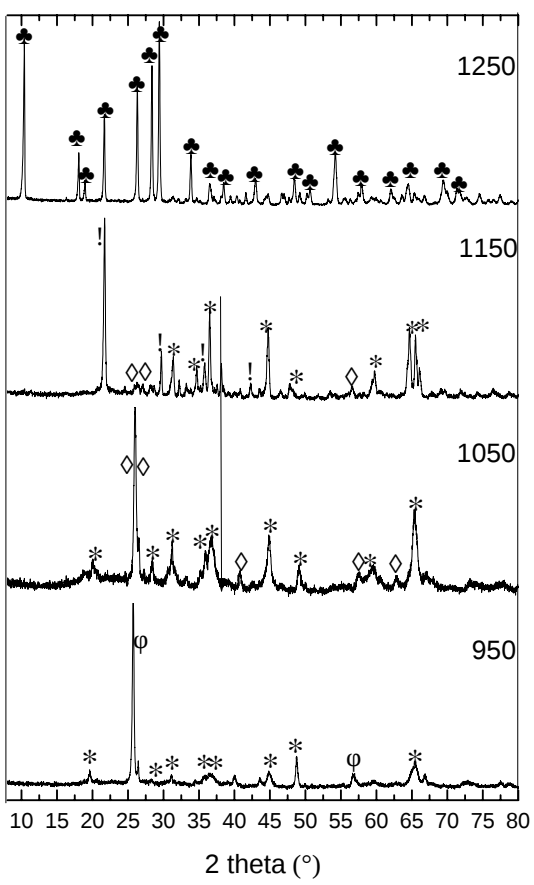

Fig. 2. XRD analysis of DTM powder heat treated at different temperatures for $2 \mathrm{~h}(\varphi$ : aluminum silicate, $\diamond$ : mullite, ${ }^{*}$ : sapphirine, !: cristobalit, o: $\alpha$-cordierite).

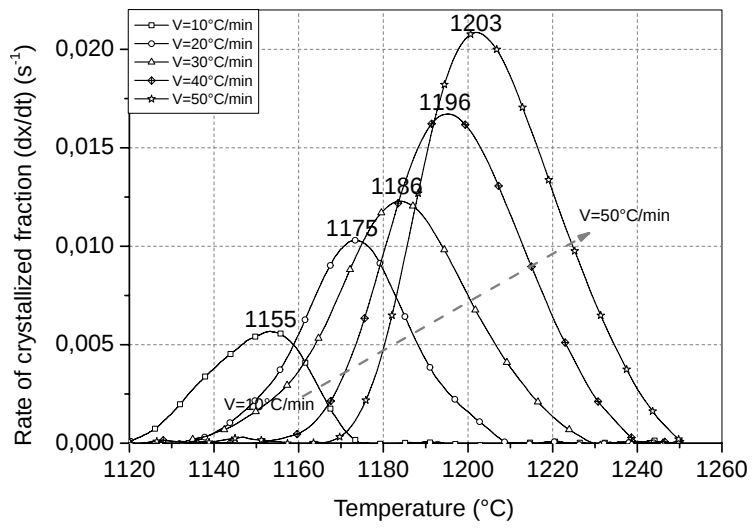

Fig. 3. DTA curves for a DTM powder processed under different heating rates.

sus temperature for various heating rates. Here $A_{T}$ is the area of the exothermic peak between the temperature $T$ and the temperature where the crystallization has just begun, $A_{0}$ is the total area under the peak between the temperature where crystallization began and the temperature where the crystallization finished. The result is presented in Fig. 4a.

The rate of crystallized fraction as a function of time at different heating rates is shown in Fig. 4b. The rate of crystallization increases with increasing heating rate from 10 to $50^{\circ} \mathrm{Cmin}^{-1}$. The Johnson-Mehl-Avrami theory describes the evolution of crystallized fraction $x$ with the time $t[12-14]$ : 

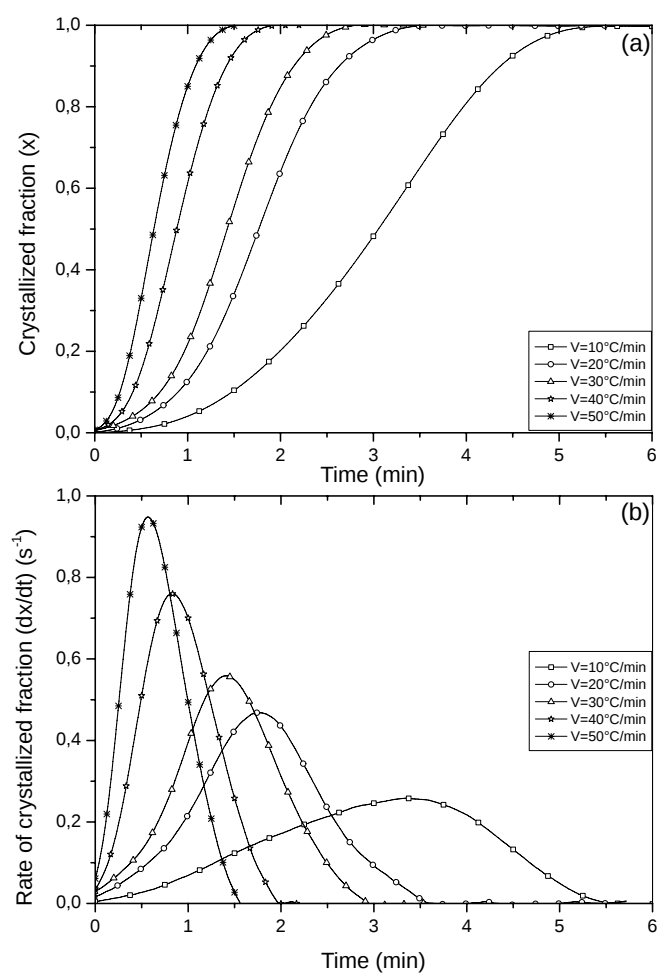

Fig. 4. Crystallized fraction and rate of crystallized fraction at different heating rates.

$x=1-\exp \left[(-k t)^{n}\right]$.

Here $x$ is the crystallized fraction at a given temperature at time $t ; n$ is the Avrami parameter, $k$ is the reaction rate constant, given by

$$
k=k_{0} \exp \left(-\frac{E_{\mathrm{A}}}{R T}\right),
$$

where $k_{0}$ is the frequency factor, $R$ is the ideal gas constant, $E_{A}$ is the activation energy and $T$ is the temperature.

Equations (1) and (2) lead to Eq. (3):

$$
\begin{gathered}
\ln \left(\frac{\mathrm{d} x}{\mathrm{~d} t}\right)=\ln \left(k_{0} n\right)+\frac{n-1}{n} \ln [-\ln (1-x)] \\
+\ln (1-x)-\frac{E_{\mathrm{A}}}{R T}=\ln \left[k_{0} f(x)\right]-\frac{E_{\mathrm{A}}}{R T} .
\end{gathered}
$$

Figure 5 presents the plot of (a): $Y=\ln (\mathrm{d} x / \mathrm{d} t)$ and (b): $Y=1 / T$ versus the crystallized fraction $x$ at various heating rates, obtained from the DTA experiment. If the same value of crystallized fraction $x$ at different heating rates is selected and $\ln (\mathrm{d} x / \mathrm{d} t)$ is plotted as function of $1 / T$, the activation energy, $E_{\mathrm{A}}$ can be calculated from the slope of the plots. These values are shown in Fig. 6a and in Table I. The activation energies of $\alpha$-cordierite are in the range of $350-384 \mathrm{~kJ} \mathrm{~mol}^{-1}$ with average equal to $372 \mathrm{~kJ} \mathrm{~mol}^{-1}$.

This value is close to the values of $438,348.85$ and $340-498 \mathrm{~kJ} \mathrm{~mol}^{-1}$ determined in [15-17], respectively.
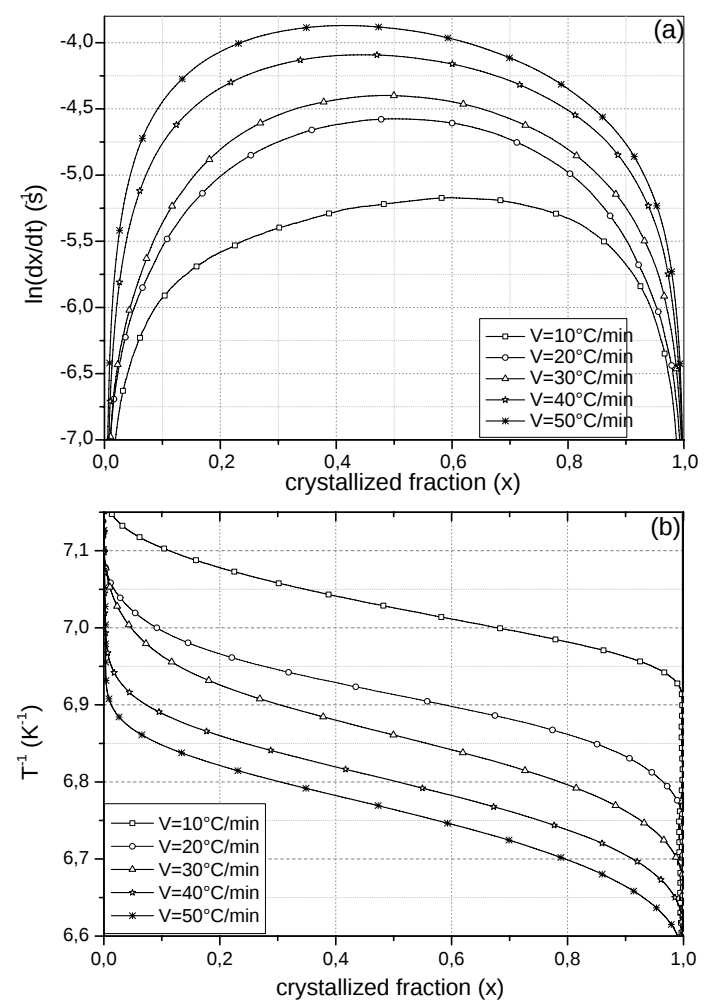

(a)

Fig. 5. Plot of $Y=\ln (\mathrm{d} x / \mathrm{d} t)$ (a) and $Y=1 / T$ (b) vs. the crystallized fraction $x$ at different heating rates.
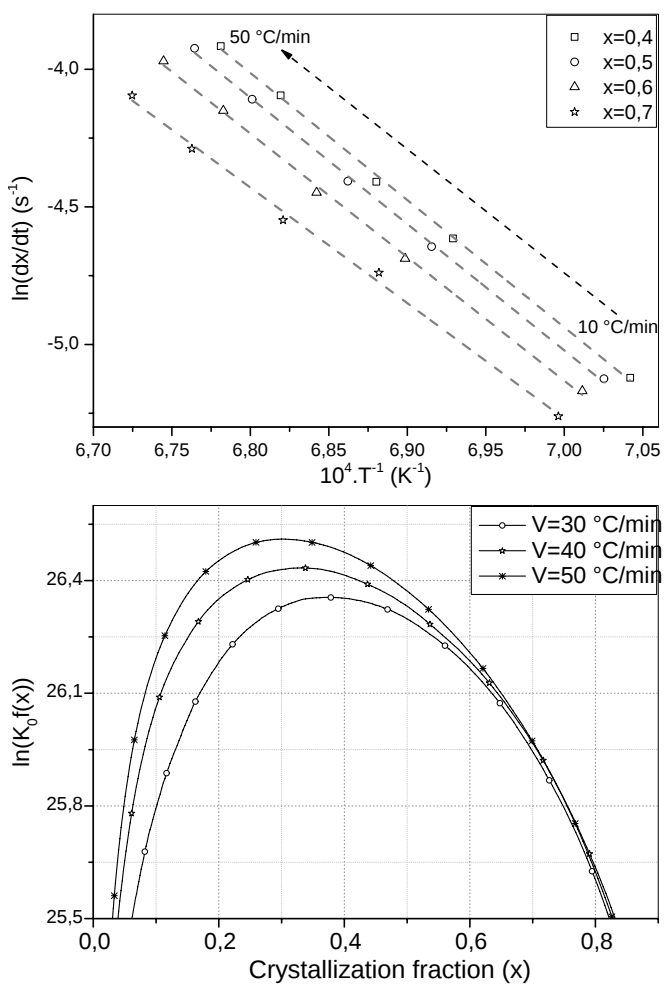

Fig. 6. Plot of $\ln (\mathrm{d} x / \mathrm{d} t)$ vs. $1 / T$ and $\ln \left[k_{0} f(x)\right]$ vs. crystallized fraction $x$ at different heating rates. 
The Avrami parameter $n$ was determined by the selection of numerous pairs of $x_{1}$ and $x_{2}$ that satisfied the condition $\left[k_{0} f\left(x_{1}\right)\right]=\ln \left[k_{0} f\left(x_{2}\right)\right]$ and by using Eq. (3), as follows:

$$
n=\frac{\ln \left[\ln \left(1-x_{2}\right) / \ln \left(1-x_{1}\right)\right]}{\ln \left[\left(1-x_{2}\right) \ln \left(1-x_{2}\right) /\left(1-x_{1}\right) \ln \left(1-x_{1}\right)\right]} .
$$

Figure $6 \mathrm{~b}$ presents the plot of $\ln \left[k_{0} f(x)\right]$ versus crystallization fraction $x$ for DTM powder heated at different heating rates. The Avrami parameter $n$ was calculated from the plot of the curve. Its average is around 1.95 for each heating rate and is given in Table II. The average value of $t_{0.75} / t_{0.25}$ for each heating rate, as shown in Table II is equal to 1.81. This suggests a two dimensional growth during the DTM powder crystallization [12-14].

TABLE I

Values of $E_{\mathrm{A}}$ and $R^{2}$ for different crystallized fractions, $E_{\text {aver }}=372 \mathrm{~kJ} \mathrm{~mol}^{-1}$.

\begin{tabular}{c|c|c|c|c}
\hline \hline crystallized fractions $x$ & 0.4 & 0.5 & 0.6 & 0.7 \\
\hline Coefficient of determination $R^{2}$ & 0.998 & 0.997 & 0.998 & 0.995 \\
Activation energy $E_{\mathrm{A}}\left[\mathrm{kJ} \mathrm{mol}^{-1}\right]$ & 384 & 381 & 373 & 350
\end{tabular}

TABLE II

Values of the Avrami parameter and $t_{0.75} / t_{0.25}$ value for different heating rates, $n_{\text {aver }}=1.95$, $\left(t_{0.75} / t_{0.25}\right)_{\text {aver }}=1.81$.

\begin{tabular}{c|c|c}
\hline \hline $\begin{array}{c}\text { Heating rate } \\
{\left[{ }^{\circ} \mathrm{C} \mathrm{min}^{-1}\right]}\end{array}$ & $\begin{array}{c}\text { Avrami } \\
\text { parameter, } n\end{array}$ & $t_{0.75} / t_{0.25}$ \\
\hline 10 & 2.10 & 1.72 \\
20 & 1.97 & 1.70 \\
30 & 1.95 & 1.76 \\
40 & 1.90 & 1.86 \\
50 & 1.81 & 2
\end{tabular}

\section{Conclusions}

In this study, cordierite ceramics was prepared by solid-state reaction from Algerian raw materials. The crystallization kinetic and growth morphology parameters have been studied by isothermal DTA analysis. The calculated activation energy of cordierite formation is found to be $372 \mathrm{kJmol}^{-1}$. The value of the Avrami parameter $n$ is around 1.95, which means that bulk nucleation was dominant in cordierite crystallization followed by $2 \mathrm{D}$ growth with plate morphology controlled by the interface reaction from constant number of nuclei.

\section{References}

[1] K. Watanabe, E.A. Giess, J. Non-Cryst. Solids 169, 306 (1994).

[2] R. Bejjaoui, A. Benhammou, L. Nibou, B. Tanouti, J.P. Bonnet, A. Yaacoubi, A. Ammar, Appl. Clay Sci. 49, 336 (2010).

[3] J. Banjuraizah, M. Hasmaliza, A.A. Zainal, J. Alloy. Compd. 482, 429 (2009).

[4] E. Yalamaç, S. Akkurt, Ceram. Int. 32, 825 (2006).

[5] J. Zhou, Y. Dong, S.Hampshire, G. Meng, Appl. Clay Sci. 52, 328 (2011).

[6] A.M. Menchi, S.N. Scian, Mater. Lett. 59, 2664 (2005).

[7] Y. Kobayashi, K. Sumi, E. Kato, Ceram. Int. 26 , 739 (2000).

[8] H. Ohsato, J.S. Kim, C.I. Cheon, I. Kagomiya, Ceram. Int. 41, S588 (2015).

[9] M. Awano, H. Takagi, K. Kuwahara, J. Am. Ceram. Soc. 75(9), 2535 (1992).

[10] D. Kuscer, I. Bantan, M. Hrovat, B. Malic, J. Eur. Ceram. Soc. 37(2), 739 (2017).

[11] N. Obradovic, N. Đordevic, S. Filipovic, S. Markovic, D. Kosanovic, M. Mitric, V. Pavlovic, J. Therm. Anal. Calorim. 124(2), 667 (2016).

[12] M. Romero, J. Martin-Marquez, J.Ma. Rincon, J. Eur. Ceram. Soc. 26, 1647 (2006).

[13] F. Sahnoune, M. Chegaar, N. Saheb, P. Goeuriot, F. Valdivieso, Advances in Applied Ceramics 107(1), 9 (2008).

[14] F. Sahnoune, M. Heraiz, H. Belhouchet, N. Saheb, D. Redaoui, Acta Phys. Pol. A 131(3), 382 (2017).

[15] M.R. Boudchicha, F. Rubio, S. Achour, Metallurgy and Materials 24(2), 194 (2017).

[16] L. Song, J. Wu, Z. Li, X. Hao, Y. Yu, J. Non-Cryst. Solids 419, 16 (2015).

[17] A. Goel, E.R. Shaaban, F.C.L. Melo, M.J. Ribeiro, J.M.F. Ferreira, J. Non-Cryst. Solids 353, 2383 (2007). 